\title{
Агробиологические аспекты производства семенного картофеля с многослойной мульчей из мискантуса
}

\author{
Agrobiological aspects of seed potato production with the multy-layer miscanthus biomass \\ mulching
}

Николаев В.А., Хохлов Н.Ф., Анисимов А.А., Тараканов И. Г.

\section{Аннотация}

Показаны результаты сравнительного анализа эффективности выращивания семенного картофеля при размещении клубней в нижнюю часть мульчирующего слоя биомассы мискантуса гигантского (Miscanthus $\times$ giganteus) - культуры, площади которой начали активно увеличиваться на территории Российской Федерации. Цель исследования - поиск способов получения качественного посадочного материала семенного картофеля при возделывании в Центральном регионе РФ с применением мульчирования мискантусом, поскольку один из основных факторов низкой урожайности картофеля в отечественных хозяйствах - использование собственного зараженного посадочного материала. Исследования проводили методом полевого эксперимента в 2018-2019 годах на Полевой опытной станции РГАУ - МСХА имени К.А. Тимирязева. Изучали два способа посадки картофеля традиционная на гребни (контроль), и высадка в мульчу. Опыт зало-

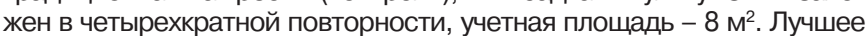
сочетание факторов для роста и развития растений при мульчировании мискантусом привело к увеличению урожайности наряду с повышением доли здоровых семенных клубней. Использование биомассы мискантуса в качестве мульчи для выращивания семенного картофеля привело к увеличению выхода здоровых кондиционных посадочных клубней. В контроле, без использования мульчи, 55\% клубней оказались поражены серебристой паршой. Кроме того, мульчирование способствовало увеличению содержания влаги в верхнем слое почвы (0-10 см) в фазу бутонизации картофеля по сравнению с традиционным способом посадки почти в два раза. У растений картофеля, выращенных при мульчировании, число стеблей на 1 га увеличилось на 12,9 тыс. шт. по сравнению с контрольным вариантом. В среднем за два года прибавка урожайности картофеля от мульчирования составила 15,2 т/га. Кроме того, мульчирование привело к увеличению выхода семенных клубней, доля которых составила 41,6\% от общей массы клубней при 30,5\% в контроле. Таким образом, способ возделывания семенного картофеля с многослойной мульчей при полосном размещении мискантуса обладает высоким потенциалом к использованию в хозяйствах для получения собственного здорового посадочного материала.

Ключевые слова: картофель, мискантус, мульча, органическое земледелие, дерново-подзолистые легкосуглинистые почвы, семенной картофель.

Для цитирования: Агробиологические аспекты производства семенного картофеля с многослойной мульчей из мискантуса / В.А. Николаев, Н.Ф. Хохлов, А.А. Анисимов, И.Г. Тараканов // Картофель и овощи. 2020. №2. С. 31-34. https://doi.org/10.25630/ PAV.2020.18.2.007
Nikolaev V.A., Khokhlov N.F., Anisimov A.A., Tarakanov I.G.

\section{Abstract}

The results of the comparative analysis of the seed potato cultivation efficiency with the use of soil surface mulching with the above-ground biomass of giant miscanthus (Miscanthus $\times$ giganteus) - a rare crop for Russian agriculture, which is beginning to spread now. The aim of the research is the searching of the methods of the qualitative seed potato getting while growing it the central part of Russian Federation with the mulching by the miscanthus biomass. One of the main factors of low yields in Russia is the usage of own infested seed potato. The researches were conducted by the means of field experiment during the vegetation seasons of 2018 and 2019 years on the territory of the Field experimental station of Russian State Agrarian University - Moscow Timiryazev Agricultural Academy. Two ways of potato planting traditional in the ranges (the control variant), and planting in the miscanthus mulch. The experiment was planned with the 4 recurrences, the registrative area was $8 \mathrm{~m}^{2}$. The usage of miscanthus biomass as a mulch for seed potato growing lead for obtaining of the healthy conditional planting tubers. In the control variant, without mulching, $55 \%$ of all tubers were affected by Helminthosporium solani. The use of miscanthus biomass mulching contributed the increase of the soil moisture in the upper layer of the soil $(0-10 \mathrm{sm})$ comparing with the traditional way of potato planting almost in 2 times. The potato plants grown with the miscanthus biomass mulching the number of stems on 1 ha increased by 12,9 thousand comparing with the control variant. The maximum potato yield $-40,7 \mathrm{t} / \mathrm{ha}$ - was marked in the variant with the miscanthus biomass mulch usage. Mulching also lead to the increase of the number of seed tubers, the part of them was $40,4 \%$ from the whole biomass. Hereby the giant miscanthus biomass can be recommended as a mulching material for the plantations of seed potato, the use of it leads to the increase of the seed potato yield and decrease the growth of the number of diseases, which can contaminate the potato plantations in the traditional way of cultivation.

Key words: potato, miscanthus, mulching, straw, organic tillage, sod-podzolic light loam soil, seed potato.

For citing: Agrobiological aspects of seed potato production with the multy-layer miscanthus biomass mulching. V.A. Nikolaev, N.F. Khokhlov, A.A. Anisimov, I.G. Tarakanov. Potato and vegetables. 2020. No2. Pp. 31-34 (In Russ.). https://doi.org/10.25630/PAV.2020.18.2.007 азработка инновационных технологий производства посадочного материала отечественных сортов картофеля - приоритетная задача агрономии в Российской Федерации. Ее решению могут содействовать комплексные разработ- ки с использованием как традиционных, так и нетрадиционных способов возделывания. К настоящему времени в европейской части Российской Федерации и Западной Сибири прошли успешные агроэкологические испытания новой высокопродуктив- ной многолетней травянистой с.- х. культуры - мискантуса гигантского (Miscanthus giganteus). Для мискантуса характерна высокая потенциальная продуктивность наземной биомассы - в первый год после высадки можно получить до 2 т сухо- 


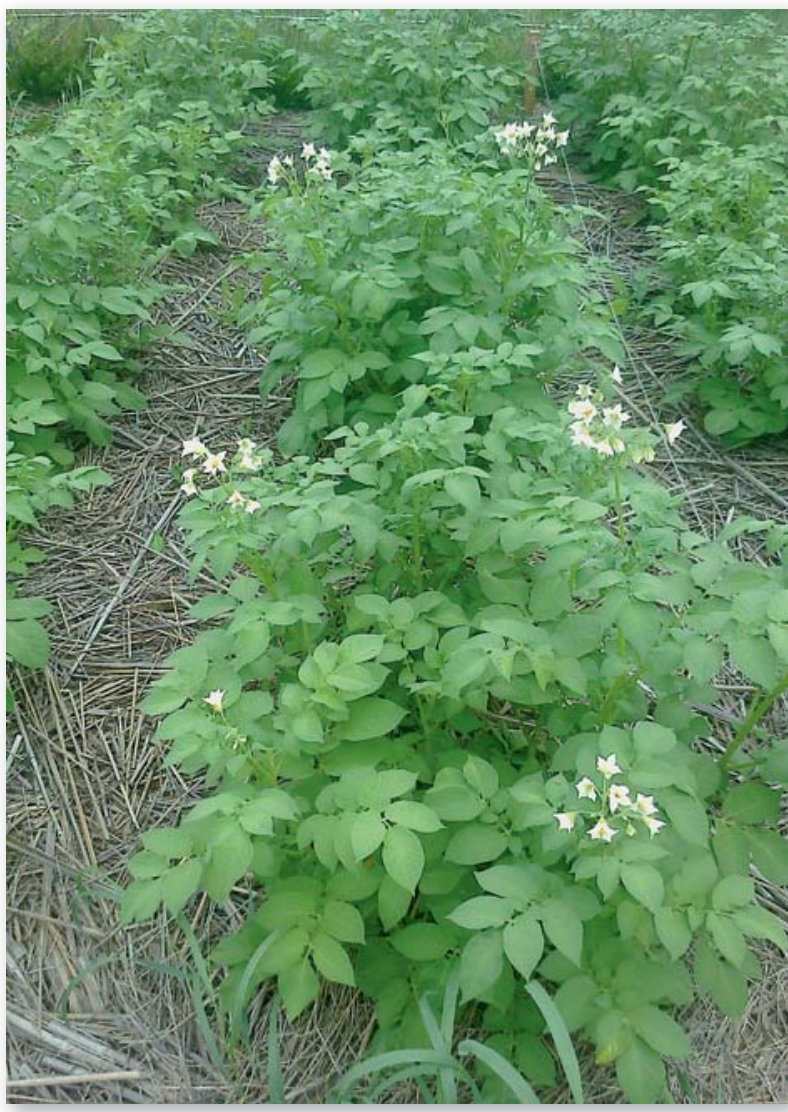

Рис. 1. Картофель, выращенный при мульчировании мискантусом

го вещества с 1 га, на 2 год - до 6-8, и на третий год - не менее 15 т/га. Мискантус гигантский - это растение с C4-типом фотосинтеза, что обуславливает его высокую потенциальную продуктивность (до 18-20 т сухой биомассы с 1 га при выходе на максимальную продуктивность к пятому году жизни). В отличие от большинства других с.- х. культур с С4типом фотосинтеза (в частности, таких, как кукуруза), ферменты темновых реакций фотосинтеза у мискантуса способны сохранять высокую активность в условиях относительно низких температур окружающей среды [1].

На сегодняшний день созданы отечественные сорта мискантуса и ведется ускоренное производство маточного материала для дальнейшего размножения [2]. Это создает условия не только для закладки плантаций для обеспечения промышленности лигниноцеллюлозным сырьем, но и для решения приоритетных задач с. - х. производства.

Установлено, что в экологических условиях Центрального региона РФ растения мискантуса практически не поражаются ни болезнями, ни вредителями, а повышенное содержание лигнина в биомассе, а также особенности морфологического строения стебля, препятствуют ее быстрому разрушению. Все это позволяет использовать наземную часть мискантуса в качестве сверхгигиеничной, многократно используемой мульчи. Поиски возможностей использования этого достоинства фермерами и владельцами ЛПХ привели к разработке технологии двойного мульчирования биомассой мискантуса при размножении картофеля.

Основные причины, лежащие в основе постановки цели исследования нижеследующие.

При размножении оригинальных ceмян в первом минимуме стоит выход семенной фракции здоровых клубней, а не высокий валовой сбор товарного картофеля;

Высокая продуктивность мискантуса позволяет создавать экономически рациональные (с высокой долей посадок картофеля) агротехнологические конструкты, исключающие расходы на транспортировку мульчи. Теоретически это возможно за счет создания чередующихся полос картофеля и мискантуса.

Мульчирование это один из основных приемов органического земледелия, положительно влияющий на агрономические свойства почвы. Этот прием увеличивает запасы влаги, регулирует температуру, уменьшает засоренность, удобряет почву при разложении, сохраняет порозность, снижает агрофизическую и агрохимическую деградацию. Создание эффективного мульчирующего слоя стабилизирует фитоса- нитарное состояние посевов, размножение и активную жизнедеятельность почвенной биоты и, как следствие, саморазрыхление почвенного слоя.

Сегодня для размножения здорового картофеля с сохранением сортовых качеств элиты и суперэлиты используют дорогостоящие лабораторные методы in vitro [3]. Из-за недостатка отечественного качественного семенного картофеля большинство хозяйств покупают импортный посадочный материал. Однако значительная часть семенного материала размножается традиционными методами. Согласно ГОСТ 33996-2016 в семенном картофеле не допускается наличие вредителей, а также клубней, пораженных болезнями.

Известно, что основной источник заражения клубней картофеля - почва. В связи с этим основная идея нашего исследования - создание оптимальных условий роста и развития картофеля с исключением контакта посадочного материала с почвой. В качестве мульчирующего покрытия поверхности поля и высаженных клубней картофеля использовали биомассу мискантуса.

Цель исследования - найти способ получения качественного посадочного материала клубней картофеля при возделывании на дерновоподзолистой легкосуглинистой почве с применением мульчирования биомассой мискантуса.

Условия, материал и методы исследований

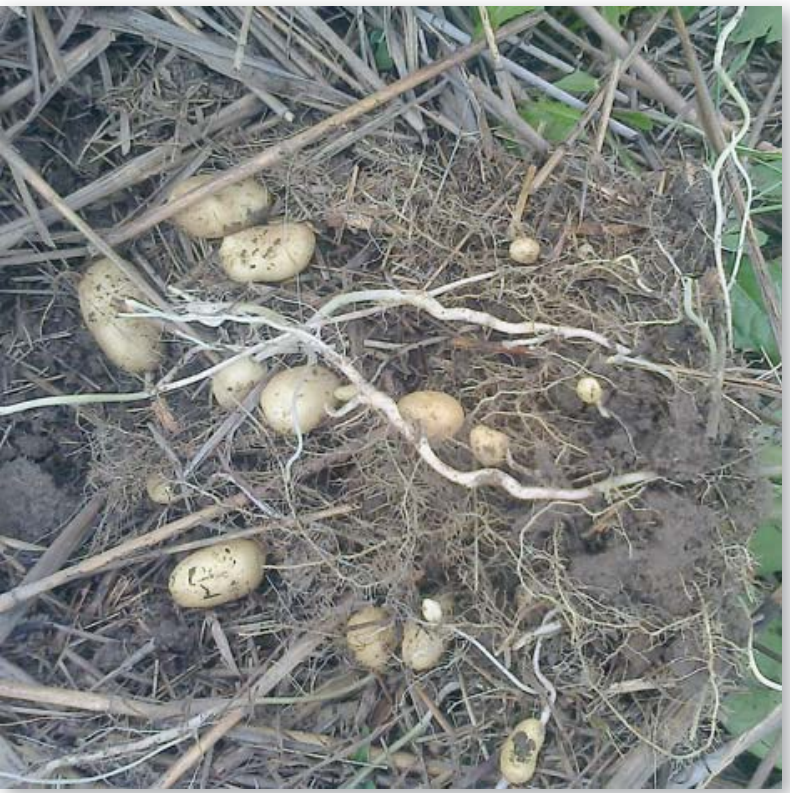

Рис. 2. Клубни картофеля, выросшие при мульчировании мискантусом 
Таблица 1. Весовая влажность почвы (\%) под контрастными. Если средкартофелем в слое 0-10 см в фазу бутонизации, немесячная температусреднее за 2019-2020 годы

\begin{tabular}{|l|c|}
\hline \multicolumn{1}{|c|}{ Вариант } & Влажность, \% \\
\hline Гребневая посадка (контроль) & 11,7 \\
\hline Посадка в мульчу (солома мискантуса) & 23,8 \\
\hline Критерий $\mathrm{T}_{05 \text { крит. }} 2,44$ & $\begin{array}{c}\mathrm{T}_{05 \Phi} \\
\mathrm{p}=0,0001\end{array}$ \\
\hline
\end{tabular}
ра воздуха за период вегетации в 2019 году составила $16,1^{\circ} \mathrm{C}$, что оказалось выше среднемноголетних значений, то за тот же период в 2018 году среднемесячная температура воздуха была существенно ниже

Исследования проводили в 2018-2019 годах на Полевой опытной станции РГАУ - МСХА имени К.А.Тимирязева. Почвенный покров опытного участка представлен дерново-подзолистыми легкосуглинистыми почвами. Содержание гумуса в пахотном слое (0-20 см) - от 2,0 до 2,5\% (по Тюрину), обеспеченность общим азотом (по Корнфилду) низкая - 35,5 мг/кг почвы, тогда как обеспеченность подвижным фосфором (по Кирсанову) высокая - (200250 мг/кг почвы). Содержание об- среднемноголетних значений.

В то же время, с точки зрения количества выпавших осадков, 2019 год оказался более сухим по сравнению с 2018 годом. В течение всех месяцев вегетационного периода количество осадков оказалось меньше среднемноголетних значений, причем наибольшее снижение количества осадков отмечено в августе 2019 года. По сравнению с 2019 годом, количество осадков за период вегетации 2018 года оказалось выше среднемноголетних

Таблица 2. Высота и густота и стеблестоя, количество заложившихся клубней картофеля в фазу цветения, в среднем за 2018-2019 годы

\begin{tabular}{|c|c|c|c|}
\hline Способ посадки & $\begin{array}{c}\text { Высота растений, } \\
\text { см }\end{array}$ & $\begin{array}{c}\text { Густота стеблестоя, } \\
\text { тыс. шт/га }\end{array}$ & Клубни, шт/куст \\
\hline $\begin{array}{l}\text { Гребневая посадка } \\
\text { (контроль) }\end{array}$ & 33,2 & 135,2 & 9,0 \\
\hline $\begin{array}{l}\text { Посадка в мульчу } \\
\text { мискантуса }\end{array}$ & 41,2 & 163,2 & 14,8 \\
\hline $\begin{array}{l}\text { Критерий } \\
\text { T }_{05} \text { крит. 2,45 }\end{array}$ & $T_{05} \phi=-2,77, p=0.03$ & $\begin{array}{c}T_{05} \phi=-9,92 \\
p=6,06 \mathrm{E}-05\end{array}$ & $T_{05} \phi=-3,58, p=0,02$ \\
\hline
\end{tabular}

менного калия (по Масловой) средняя (150-200 мг/кг почвы). pН водной вытяжки колебался в пределах от 5,8 до 6,2.

Изучали два варианта посадки элитного картофеля (сорт Ресурс) традиционная гребневая (контроль) и посадка в нижнюю часть десятисантиметрового слоя мульчи из мискантуса.

Опыт заложен в четырехкратной повторности. Учетная площадь делянки - 8,0 м².

Статистическую обработку данных проводили на ЭВМ с использованием t-критерия.

Метеорологические условия вегетационного периода 2018 и 2019 года оказались достаточно продуктивное испарение почвенной влаги [2].

\section{Результаты исследований}

Использование мульчи из соломы мискантуса по сравнению с традиционной гребневой посадкой обеспечивало увеличение содержания влаги в слое почвы 0-10 см в два и более раза (табл. 1). Это достигалось тем, что покрытая мульчей выровненная поверхность поля не только сокращала испарение, но, в отличие от открытых гребневых посадок, быстро впитывала летние ливневые осадки, что препятствовало эрозии.

Одна из основных характеристик потенциальной продуктивности посадок картофеля - число стеблей на 1 га. В условиях отсутствия сорных растений (рис. 1) и более благоприятного водного режима, в критический период при мульчировании, к фазе цветения сформировались высокие, полноценно развитые растения картофеля. В среднем за два года применение мульчи способствовало увеличению высоты растений (41,2 см) разница составила 7-8 см в пользу варианта с мульчированием мискантусом.

Густота стеблестоя растений картофеля в опыте в среднем за годы исследований колебалась от 135 до 163 тыс. шт/га. При посадке клубней в мульчу этот показатель был на 28,1 тыс. шт/га, или на 20,7\%, выше по сравнению с контролем.

Лучшие гидротермические условия в критические периоды способствовали образованию большего числа клубней. При посадке в мульчу количество клубней составило 14,8 шт. с одного растения, при этом на варианте с гребневой посадкой число клубней составило 9,0 шт/куст (табл. 2).

Таким образом, при традиционном возделывании наряду с относительно слабым развитием надземной массы формируется и более низкое число клубней с одного куста.

Один из основных факторов низкой урожайности картофеля в отечественных хозяйствах - использование собственного зараженного по-

Таблица 3. Урожайность, структура урожая и доля больных клубней картофеля сорта Ресурс, в среднем за 2018-2019 годы

\begin{tabular}{|c|c|c|c|c|c|}
\hline \multirow{2}{*}{ Вариант } & \multirow{2}{*}{ Урожайность, т, га } & \multicolumn{3}{|c|}{ Доля, клубней в урожае, \% } & \multirow{2}{*}{$\begin{array}{c}\text { Доля больных } \\
\text { клубней,\% }\end{array}$} \\
\hline & & Крупных (>80 г) & Мелких (<30 г) & Семенных (30-80 г) & \\
\hline $\begin{array}{l}\text { Гребневая посадка } \\
\text { (контроль) }\end{array}$ & 25,5 & 43,7 & 25,8 & 30,5 & 61,2 \\
\hline $\begin{array}{l}\text { Посадка в мульчу } \\
\text { мискантуса }\end{array}$ & 40,7 & 38,4 & 20,0 & 41,6 & 2,3 \\
\hline Критерий $\mathrm{T}_{\text {05 крит. }}=2,12$ & $\begin{array}{c}\mathrm{T}_{05 \phi}=-3,7, \mathrm{p}=0,01, \\
\mathrm{~T}_{\text {крит. }}=2,57 \\
=2,57\end{array}$ & - & - & - & $\mathrm{T} \phi=3,8$ \\
\hline
\end{tabular}


садочного материала. Поэтому важнейшее профилактическое мероприятие - поддержание здорового семенного материала, что прежде всего зависит от условий его выращивания $[4,5]$.

По результатам исследований мы установили, что при широком диапазоне контрастных метеорологических условий вегетационного периода 2018-2019 годов лучшее сочетание факторов жизни растений при мульчировании мискантусом привело к увеличению урожайности с повышением доли здоровых семенных клубней (табл. 3). При средней урожайности на контроле 25,5 т/га, прибавка от мульчирования составила 15,2 т/га или 59,6\%. К тому же, их пораженность серебристой паршой составила 2,3\% (рис. 2). С учетом выхода семенной фракции (30,5\% на контроле и 41,6\% при мульчировании)

\section{Библиографический список}

1.Анисимов А.А., Хохлов Н.Ф., Тараканов И.Г. Особенности фотопериодической регуляции онтогенеза у различных видов мискантуса (Miscanthus spp.) // Известия TCXA. 2016. №6. C. 56-72.

2.Дорогина О.В. и др. Ресурсный потенциал некоторых видов рода Miscanthus Anderss. в условиях континентального климата лесостепи Западной Сибири // Вавиловский журнал генетики и селекции. 2018. Т. 22. №5. С. 553-559.

3.Лапшинов Н.А. Урожайность картофеля в зависимости от влагообеспеченности // Достижения науки и техники АПК. 2009. №3. С. $26-28$.

4.Анисимов Б.В., Усков А.И. Семеноводство картофеля в России: состояние, проблемы и перспективы направления // Достижения науки и техники АПК. 2007. №7. С. 15-19.

5.Сушенкова Н.Ю., Сорокина С.Ю. Нетрадиционные технологии в решении проблем минимилизации обработки почвы // Вестник сельского развития и социальной политики. 2016. №4 (12). С. 75-77.

\section{Об авторах}

Николаев Владимир Антонович, канд с. - х. наук, доцент каф. земледелия и МОД E-mail: vladimir_nikolaev0202@mail.ru

Хохлов Николай Федорович, доктор с.- х. наук, профессор каф. земледелия и МОД. E-mail: hohlov@rgau-msha.ru

Анисимов Александр Алексеевич, ассистент каф. физиологии растений E-mail: alanis152@mail.ru

Тараканов Иван Германович, доктор биол. наук, профессор каф. физиологии растений. E-mail: plantphys@rgau-msha.ru ФГБОУ ВО РГАУ - МСХА именИ К.А. Тимирязева сбор семян составил на контроле 7,77 т/га, а при мульчировании 16,93 т/га, т.е. прибавка от мульчирования составила $117 \%$. Эти данные не включают поправку на коэффициент реальной площади при полосных посевах. Однако даже при максимально высокой площади мискантуса, необходимого для мульчирования, этот коэффициент не будет превышать в Центральном Нечерноземье значения 0,25.

\section{Выводы}

Таким образом, способ возделывания семенного картофеля с многослойной мульчей при полосном размещении мискантуса обладает высоким потенциалом к использованию в хозяйствах для получения собственного здорового посадочного материала.

\section{References}

1.Anisimov A.A., Khokhlov N.F., Tarakanov I.G. Peculiarities of photoperiodic regulation of different miscanthus genotypes onthogenesis. RSAU news. 2016. №6. Pp. 56-72 (In Russ.)

2.Dorogina O.V. et al. Resourse potential of some species of Miscanthus Anderss. Geners in the conditions of continental climate of Western Siberia. Vavilov journal of genetics and selection. 2018. Vol. 22. №5. Pp. 553-559 (In Russ.).

3.Lapshinov N.A. Potato yield depending on the water content. Achievements of science and technology in agriculture. 2009. №3. Pp. 26-28 (In Russ.).

4.Anisimov B.V., Yskov A.I. Seed potato growing in Russia: terms, problems and destinations. Achievements of science and technology in agriculture. 2007. №7. Pp. 15-19 (In Russ.)

5.Sushenkova N.Y., Sorokina S.Y. Nontraditional technologies in solving the problem of minimization of soil tillage. Bulletin of rural development and social policy. 2016. №4 (12). Pp. 75-77 (In Russ.).

\section{Author details}

Nikolaev V.A., Cand. Sci. (Agr.), associate professor of department of tillage and methods of research. E-mail: vladimir_ nikolaev0202@mail.ru

Khokhlov N.F., D. Sci. (Agr.), professor of department of tillage and methods of research. E-mail: hohlov@rgau-msha.ru

Anisimov A.A., assistant professor of department of plant physiology. E-mail: alanis152@mail.ru

Tarakanov I.G., D. Sci. (Biol.), professor of department of plant physiology. E-mail: plantphys@rgau-msha.ru

Russian State Agrarian University Moscow Timiryazev Agricultural Academy after K.A. Timiryazev

\section{Новые сорта картофеля отечественной селекции}

Селекционеры Башкирского ГАУ представили три новых высокоурожайных сорта картофеля

Ученые Башкирского государственного аграрного университета продолжают плодотворную работу по выведению новых видов картофеля на безвирусной основе. Так, селекционеры вуза представили три высокоурожайных сорта Эрвел, Агата НС и Ирендык, прекрасно адаптированных к климату Приволжского федерального округа и устойчивых к различным заболеваниям.

Главное преимущество сорта Эрвел - мощная корневая система, которая превосходит стандартные показатели в два раза и составляет 5\%, универсальность (картофель пригоден как для пищи, так и в качестве сырья), засухоустойчивость и иммунитет к вредителям.

Агата НС и Ирендык отличаются высоким содержанием крахмала (21\% и выше) и витамина С (2028 мг \%). Продуктивность Агаты к тому же достигает до 20 т, составив в 2019 году 12,4 т/га, или более 2,5 кг с каждого куста. По словам создателя, главного научного сотрудника Башкирского ГАУ Дениса Андрианова, оба этих сорта даже после механической и тепловой обработки сохраняют свой первоначальный цвет на протяжении более пяти суток.

Кроме того, все новинки значительно дешевле как отечественных, так и зарубежных образцов в среднем на $12 \%$, что позволит существенно снизить уровень импортозависимости и увеличить производство элитного семенного материала картофеля до 30 тыс. штук ежегодно.

Сегодня для сорта Эрвел готовится патент, а Агата НС и Ирендык переданы для внесения в государственный реестр селекционных достижений. Отметим также, что еще четыре новые линии картофеля ученых Башкирского ГАУ проходят госсортоиспытания по Российской Федерации.

Источник: www.mcx.ru 